\title{
Economic feasibility analysis of commercial formaldehyde-based adhesives
}

\author{
Minliang Yang ${ }^{1} \cdot$ Kurt A. Rosentrater ${ }^{2}$ (I)
}

Received: 18 January 2020 / Accepted: 19 June 2020 / Published online: 30 June 2020

(c) Springer Nature Switzerland AG 2020

\begin{abstract}
Formaldehyde-based adhesives have been used for several decades due to its convenience. In this paper, we aimed to explore the economics of urea-formaldehyde (UF) adhesives that can be used in wood panels. Two formaldehyde production pathways: metal oxide pathway and silver pathway, were compared in this study. SuperPro Designer v9.5 software was employed to perform the techno-economic analysis (TEA). Key parameters of TEA were calculated and compared of these two pathways, including total capital investment, annual operating cost and product revenues. It was found that the unit production cost of UF adhesive made from metal oxide pathway $(\$ 0.86 / \mathrm{kg})$ was less expensive than that from silver pathway $(\$ 0.99 / \mathrm{kg})$, but the total capital cost was slightly higher in metal oxide pathway (40 million $\$$ ) than silver pathway (38 million \$). Additionally, sensitivity analysis indicated that final product yield and material costs were the most sensitive factors among all inputs.
\end{abstract}

Keywords Techno-economic analysis (TEA) · Urea-formaldehyde adhesive (UF adhesive) · Metal oxide pathway · Silver pathway

\section{Introduction}

Resin made from urea formaldehyde (UF) polymer began commercial use as adhesives in the 1920s [1]. Afterwards, UF adhesive became one of the most widely used adhesive worldwide. Every year, there are more than 13 billion tons of adhesive produced [2]. Approximately more than $70 \%$ of UF adhesives are used for bonding purpose in forest product industries, such as medium-density fiberboard, hardwood plywood, and particleboard [3]. UF adhesive is one type of the amino resins with excellent tensile strength, hardness and impact resistance [4]. Amino resins could be used in molding products and it has the ability to modify the properties of materials. For instance, in textile fabrics production process, it could help to increase the permanent-press characteristics [5].
UF adhesive is consisted of linear or branched oligomer and polymeric molecules. In industrial production, UF adhesive is made by the condensation of formaldehyde and urea in an aqueous solution. Although it is only composed of urea and formaldehyde, the formation reactions of UF adhesive are quite complex [6]. Different conditions and molar ratio of urea to formaldehyde may result various condensed products. There are usually two synthesis steps. First, urea and formaldehyde react to form mono-methylolurea, with some di-methylolurea and tri-methylolurea; then, these products are condensed to low molecular weight polymers. The condensation reaction could give a colorless solution that can be dried to powder. The final product is then distilled until $65 \%$ solids UF adhesive is achieved [6].

Kurt A. Rosentrater, karosent@iastate.edu; Minliang Yang, minlyang@iastate.edu | ${ }^{1}$ Department of Agricultural and Biosystems Engineering, lowa State University, 3326B Elings Hall, Ames, IA 50011, USA. ${ }^{2}$ Department of Agricultural and Biosystems Engineering, lowa State University, 3327 Elings Hall, Ames, IA 50011, USA. 
The advantages of UF adhesive include low curing temperature, resistance to microbials, and resistant to electrical sources, which make it desirable for wall outlets and switch plates products [1]. Additionally, compared to other adhesives, UF adhesive is reported as the most economic one [7]. However, UF adhesive is less durable than phenol formaldehyde adhesive and lack of water resistance in exterior applications because of the amino-methylene linkage that makes it unstable under the moist conditions, especially in combination of heat [1]. Besides, hydrolysis of weakly bound compounds may lead to the reverse reaction, which could result in the formaldehyde emission from the UF-bonded product [8].

Formaldehyde $\left(\mathrm{CH}_{2} \mathrm{O}\right)$, one of the most important precursors to many industrial chemicals, has been synthesized in Germany in late nineteenth century. Several years later, formaldehyde production from the mixture of methanol vapor and air became possible in industrial scale. It is found that the ratio of methanol and air as well as the catalyst employed during production has large effect on the yield of the reaction. In 1925, due to the development of methanol production from timber industry, formaldehyde has been successfully produced on a commercial scale [9]. Typically, formaldehyde is produced by two main methods: oxidation-dehydration process using silver as the catalyst and direct oxidation of methanol using metal oxide as the catalyst. Silver catalyst is the oldest approach and it is often carried out at high temperature (around $650^{\circ} \mathrm{C}$ ). As estimated in 2000 , over $50 \%$ of west European companies adopted this pathway in industrial [10]. The other process, metal oxide catalyst process is the most widely applied modern commercial process [11]. This process requires lower temperature (about $350^{\circ} \mathrm{C}$ ) and the generated heat could provide steam for process heating [12]. In this study, the two pathways are compared in order to fully investigate the strength and weakness of each pathway.

Another material, urea $\left(\mathrm{CO}\left(\mathrm{NH}_{2}\right)_{2}\right)$, serves a vital role in the chemical industry as well. According to Ceresana, the market research institute, the global urea market may increase to 96 billion \$ in 2019 [2]. Friedrich Wöhler obtained it from the reaction of silver cyanate and ammonium chloride in late nineteenth century. This has been regarded as a milestone in chemistry because it was the first time that an organic compound was artificially synthesized from inorganic materials. Urea has been broadly applied in agriculture, especially as a fertilizer. It is estimated that urea has the highest nitrogen content among all fertilizers. Urea is also used in chemical industries, especially in the manufacturing of UF adhesive and urea-melamine-formaldehyde adhesive [9].

The debate on UF adhesive has been continued throughout the last decades. Even though the limit of the formaldehyde emission has been revised, the side-effect of UF adhesive is still a concern by public [13]. Biobased adhesives have been explored in these days in order to make more environmentally friendly product [14]. However, no thorough comparison between formaldehyde adhesive and biobased adhesive has been studied in both economic and environmental perspective. Technoeconomic analysis (TEA) is a process-modeling tool to simulate the production process. TEA could not only include the technical parameters, but also economic factors into the project [15]. It starts with the material and energy balance, and then cost analysis is conducted to assess the economic feasibility of the project. As a simulation tool, the assumptions of the study are highly important. Different assumptions could lead to significantly different results. The accuracy of the result may vary in a range of $\pm 30 \%$ [16]. The objective of this study is to evaluate the economic value of the UF adhesive production process in both pilot and commercial scale. Two different pathways to produce formaldehyde (silver process pathway and metal oxide process pathway) are explored in this study. Capital investment, annual operation cost, unit production cost, gross margin, return on investment as well as payback time are discussed in this study. Comparisons will be made between the two pathways based on these economic indicators.

\section{Methods}

In this study, SuperPro Designer v9.5 software (Intelligen Inc., Cambridge, Massachusetts, USA) was employed to develop UF adhesive production processes. Five scales were analyzed: 1 t/d, 2 t/d, 5 t/d, 10 t/d and 40 t/d. The largest scale $(40 \mathrm{t} / \mathrm{d})$ has the production capacity in equivalent of around 14,000 t/yr. The selection of this scale was based on a commercial formaldehyde resin plant sold by Phoenix Equipment Corporation (plant \# 271) [17]. In addition, two formaldehyde production processes were explored and labeled as MO (metal oxide process) and S (silver process). A total of ten scenarios were investigated in this study due to the adoption of two formaldehyde production pathways. Scenario 1-5: MO process with five plant scales varied from 1 to $40 \mathrm{t} / \mathrm{d}$; Scenario 6-10: S process with five plant scales vary from 1 to $40 \mathrm{t} / \mathrm{d}$. A simplified overall flowchart of the UF adhesive production process is shown in Fig. 1.

Although not provided here due to space limitations, specific details regarding mass balances, energy consumption, and how annual sales revenues and production costs were calculated can be found in detail in [18], which compared in detail glycerol-based adhesives production to traditional adhesives manufacturing. 
Fig. 1 Simplified overall flowchart of the urea-formaldehyde adhesive production process. Pathway 1: metal oxide process. Pathway 2: silver process

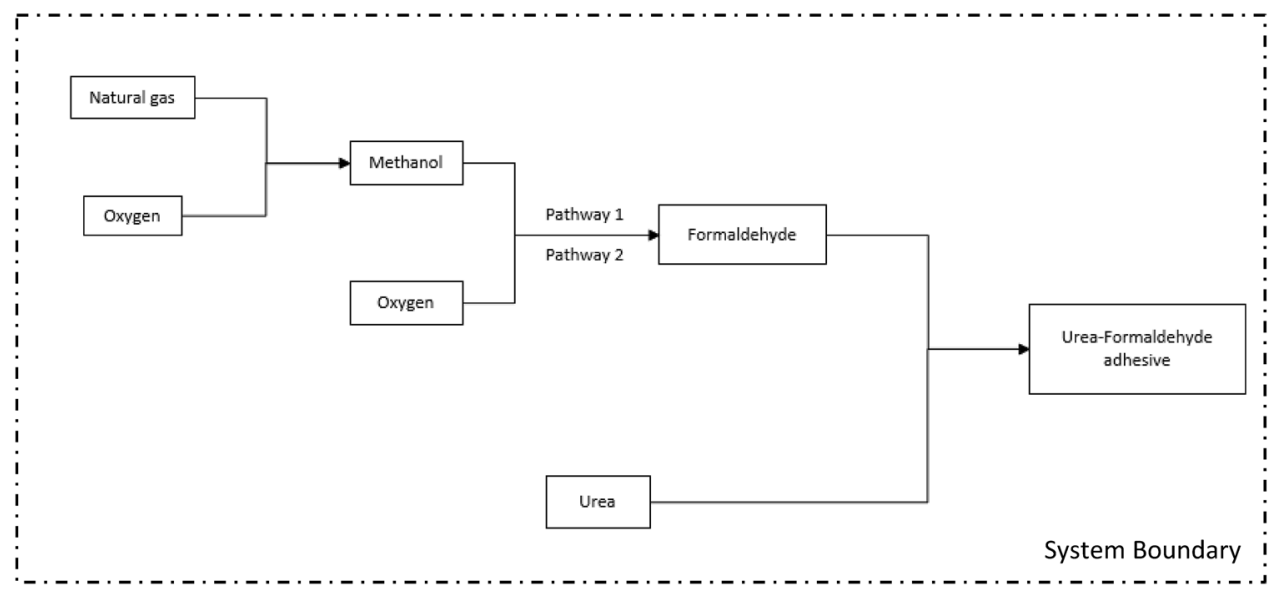

Table 1 Reaction mechanism properties [21]

\begin{tabular}{lll}
\hline Number & Reaction equations & $\Delta \mathrm{H}(\mathrm{kJ} / \mathrm{mol})$ \\
\hline 1 & $\mathrm{CH}_{3} \mathrm{OH}+0.5 \mathrm{O}_{2} \rightarrow \mathrm{HCHO}+\mathrm{H}_{2} \mathrm{O}$ & -159 \\
2 & $\mathrm{HCHO}+0.5 \mathrm{O}_{2} \rightarrow \mathrm{CO}+\mathrm{H}_{2} \mathrm{O}$ & -314 \\
3 & $\mathrm{CH}_{3} \mathrm{OH} \rightarrow \mathrm{HCHO}+\mathrm{H}_{2}$ & +84 \\
4 & $\mathrm{H}_{2}+0.5 \mathrm{O}_{2} \rightarrow \mathrm{H}_{2} \mathrm{O}$ & -242 \\
5 & $\mathrm{NH}_{2} \mathrm{CONH}_{2}+\mathrm{HCHO} \leftrightarrow \mathrm{NH}_{2} \mathrm{CONHCH}_{2} \mathrm{OH}$ & -229.9 \\
\hline
\end{tabular}

\subsection{Production process description}

The MO process has the advantage of lower pressure requirements. The production process starts with vaporization of methanol and mixing with air in the reactor. The reactions happened in the reactor can be found in Table 1 (number 1 and 2). Iron(III) oxide (Fe) and molybdenum trio (Mo) are employed as the catalysts and the ratio of Fe to Mo is approximately $1: 4$. The temperature inside the reactor is maintained at $285^{\circ} \mathrm{C}$. After nitrogen and oxygen is separated from the main stream, it is cooled down to $110^{\circ} \mathrm{C}$ following by the absorption process afterward. The formic acid is produced as the co-product in this process, and the formaldehyde is condensed as well as the methanol. The final products contain $37 \mathrm{wt} \%$ formaldehyde solution (and about $1 \mathrm{wt} \%$ methanol, to avoid the formation of paraformaldehyde for our production process). As for the $\mathrm{S}$ process, many patents described the conventional production process $[19,20]$. In this study, the silver process begins with the mixing of methanol and air, and the ratio between methanol and air is about $40 \%$. Initial air pressure is set to be $0.2 \mathrm{~atm}$. In addition, the mixture temperature is maintained at $550^{\circ} \mathrm{C}$ in the reactor (number 3 in Table 1). Hydrogen is produced and separated in the following step. Then the product stream is sent to the purification and recovery section. Unreacted methanol is separated from the main stream, approximately $18 \%$ of the input methanol. Same final product (37 wt \% formaldehyde) as $\mathrm{MO}$ process is also produced from $S$ process.

Based on Taylor [22], the UF adhesive production process starts with the blending of formaldehyde and urea at a molar ratio of 2.6:1; and then water is evaporated until total water content is nearly $50 \mathrm{wt} \%$. After that, urea is added to adjust the molar ratio of formaldehyde to urea to $1.5: 1$. Sodium hydroxide is added in this stage to adjust $\mathrm{pH}$ to $8-9$. At the end of this stage, methylol urea is formed as number 5 shows in the Table 1. Next step is to condensate the methylol urea to low molecular weight polymers. Acid is added to bring the $\mathrm{pH}$ to around 5 . Water is removed by distillation in order to reach a desire solid resin content to $65 \%$.

The reactors were equipped with heating and cooling systems, mechanical stirrers, and a vacuum system, while the additions of raw materials is continuous. Crucial is the purity of raw materials, F-to- $U$ molar ratio, and the control of production parameters $(\mathrm{pH}$, reaction $\mathrm{T}$ and reaction $t$, and sequence of addition of the raw materials). Although not provided here due to space limitations, specific details regarding mass balances, energy consumption, and how annual sales revenues and production costs were calculated can be found in detail in [18]. That study compared manufacturing of bio-based adhesives from glycerol to manufacturing of traditional adhesives. The reader is referred to this reference for specific details on model development and implementation.

\subsection{Techno-economic analysis}

Detail assumptions used in techno-economic analysis can be found in our other TEA paper [23]. Total capital investment $\left(C_{T C I}\right)$ is the sum of the direct fixed costs $\left(C_{D F C}\right)$ associated with the study, the startup and validation $\left(C_{S}\right)$ cost, and the working capital $\left(C_{W}\right)$ (Eq. 1). 
$C_{T C l}=C_{D F C}+C_{S}+C_{W}$

Direct fixed costs $\left(C_{D F C}\right)$ is composed of direct cost $\left(C_{D C}\right)$, indirect $\operatorname{cost}\left(C_{I C}\right)$ and other cost $\left(C_{O C}\right)$. In direct cost $\left(C_{D C}\right)$ section, piping, instrumentation, insulation, electrical facilities, buildings, yard improvement, auxiliary facilities, installation fee are considered. The equipment purchase cost is obtained from SuperPro Designer v9.5 database, other factors associated with each cost item is taken from Peters et al. [24]. Indirect cost contains engineering cost and construction cost, and other cost refers to contractor's fee and contingency fee. Working capital $\left(C_{w}\right)$ is specified as the sum of major operation cost in a certain period. $C_{w}$ is assumed $15 \%$ of the direct fixed cost. Start-up and validation $\left(\mathrm{C}_{\mathrm{s}}\right)$ cost refers to the one-time pre-opening production cost. In this study, it is estimated as $10 \%$ of the direct fixed cost.

Annual operating cost $\left(C_{A O C}\right)$ includes raw materials cost $\left(C_{M}\right)$, labor cost $\left(C_{L}\right)$, utilities cost $\left(C_{U}\right)$, and facility-dependent $\operatorname{cost}\left(C_{F}\right)(E q .2)$. In this study, waste treatment cost, long-term storage cost, distribution and marketing cost, research and development (R\&D) cost are not considered. Major assumptions for the annual operating $\operatorname{cost}\left(\mathrm{C}_{\mathrm{AOC}}\right)$ are listed in Table 2 .

$C_{A O C}=C_{M}+C_{L}+C_{U}+C_{F}$

The material cost $\left(C_{M}\right)$ is obtained from the retailer websites. Silver catalyst cost is the average price of the silver-based catalyst sold by the Sigma-Aldrich Company.

Table 2 Assumptions used in annual operating cost analysis

\begin{tabular}{|c|c|c|}
\hline Parameters & Assumption & Source \\
\hline \multicolumn{3}{|l|}{ 1. Materials cost $\left(C_{M}\right)$} \\
\hline Methanol & $0.55 \$ / \mathrm{kg}$ & {$[25]$} \\
\hline Silver catalyst & $300 \$ / \mathrm{kg}$ & {$[25]$} \\
\hline Iron oxide & $0.71 \$ / \mathrm{kg}$ & {$[25]$} \\
\hline Molybdenum oxide & $15.5 \$ / \mathrm{kg}$ & {$[25]$} \\
\hline Urea & $0.16 \$ / \mathrm{kg}$ & {$[25]$} \\
\hline Sodium hydroxide & $0.35 \$ / \mathrm{kg}$ & {$[25]$} \\
\hline \multicolumn{3}{|l|}{ 2. Utilities cost $\left(C_{U}\right)$} \\
\hline Electricity & 5.08 cents $/ \mathrm{kWh}$ & {$[26]$} \\
\hline Steam & $12 \$ / t$ & SuperPro \\
\hline Process water & $0.05 \$ / \mathrm{t}$ & $\begin{array}{l}\text { Designer } \\
\text { v9.5 data- } \\
\text { base }\end{array}$ \\
\hline 3. Labor cost $\left(C_{L}\right)$ & & {$[27]$} \\
\hline \multicolumn{3}{|c|}{$\begin{array}{l}\text { 4. Facility-dependent cost } \\
\left(C_{F}\right)\end{array}$} \\
\hline Maintenance & $0.02 \times C_{P C}$ & {$[24]$} \\
\hline \multirow[t]{2}{*}{ Depreciation } & Straight-line method & {$[28]$} \\
\hline & Salvage value $=0$ & [29] \\
\hline Insurance & $0.01 \times C_{D F C}$ & \\
\hline Local tax & $0.02 \times C_{D F C}$ & {$[24]$} \\
\hline
\end{tabular}

Electricity price is collected from the U.S. Energy Information Agency (EIA) electricity report [26]. Other utilities costs such as steam and process water are gathered from SuperPro Designer v9.5 database. The labor cost is calculated based on the U.S. Bureau of Labor [27]. In this study, the labor cost is only operating labor cost; supervisory and administrative cost are not considered. The depreciation cost is calculated by the straight-line method. According to the Department of Treasury, the recovery period for the manufacture of chemicals and allied products is 9.5 years [28]. The salvage value of the purchased equipment in this study is 0 based on the description of Turton et al. [29].

\subsection{Profitability analysis}

A unit production cost is calculated by dividing the annual total investment by annual production amount (Eq. 3). It is used to compare the product price in a unit-base perspective: cost per kg of raw materials or products.

Unit production cost $(\$ / \mathrm{kg})=\frac{\text { Annual total investment }}{\text { Unit reference flow }}$

Gross margin is defined as the percentage of gross profit to revenues (Eq. 4). It is a type of direct measure of profit. With higher gross margin, the product is more likely to have higher profit.

Gross margin $(\%)=\frac{\text { Revenue }- \text { Cost of Goods Sold }}{\text { Revenue }} \times 100 \%$

Return on investment is another measurement of profit. It is used to evaluate the efficiency of investments. ROI is calculated as in Eq. (5). If a negative ROI value is obtained, then the investors may lose money.

$R O I(\%)=\frac{\text { Net profit }}{\text { Total investment }} \times 100 \%$

Payback time is the estimation of the time needed to recover the cost of an investment. With shorter payback time, the investment tends to be more attractive.

Payback time $($ years $)=\frac{\text { Total investment }}{\text { Net profit }}$.

\subsection{Sensitivity analysis}

Sensitivity analysis is used to explore the key input parameters to the final product value [30]. In this study, several input variables were selected based on the potential impact of the product value. Due to the uncertainty associated with the TEA study, the total capital investment was varied in the range between $\pm 30 \%$. 
Other parameters such as raw material costs, utility cost, labor cost and product yield are also investigated due to the potential influence they may have on the final unit production cost.

\section{Results and discussion}

\subsection{Techno-economic analysis result of the two pathways}

The total capital investment and annual operating cost of ten scenarios are listed in Table 3. In general, with increasing plant scales, both total capital cost and annual operating cost are increasing and the unit production cost is decreasing (Fig. 2). S process has higher annual operating cost but lower total capital investment when compared at larger plant scales with that of MO process. This leads to a relatively higher unit production cost from $S$ process than $\mathrm{MO}$ process as can be observed in Fig. 2 . Higher operating cost obtained in S process is due to the higher price of raw material, silver in this process. In addition, higher steam temperature $\left(\sim 600^{\circ} \mathrm{C}\right)$ is required in $\mathrm{S}$ process, which increases the annual operating cost as well. More specifically, the capital cost of MO process follows the trend line: $y=5 E+06 \times X^{0.561}$ with $R^{2}=0.97$ and S process follows: $y=6 E+06 \times X^{0.48}$ with $R^{2}=0.99$. Corresponding unit production cost of $\mathrm{MO}$ process had the trend line: $y=2.26 \times X^{-0.287}$ with $R^{2}=0.92$, while the $S$ process had the trend line:

$y=2.56 \times X^{-0.29}$ with $R^{2}=0.90$. The lowest unit cost obtained in MO process is $\$ 0.86 / \mathrm{kg}$ from Scenario 5 with the plant scale of $40 \mathrm{t} / \mathrm{d}$. In $\mathrm{S}$ process, the lowest unit production cost is $\$ 0.99 / \mathrm{kg}$ from Scenario 10 with the plant scale of $40 \mathrm{t} / \mathrm{d}$.

Table 3 Total capital investment and annual operating cost of ten scenarios

\begin{tabular}{lcr}
\hline Scenario & $\begin{array}{l}\text { Total capital invest- } \\
\text { ment }(\$)\end{array}$ & $\begin{array}{r}\text { Annual oper- } \\
\text { ating cost }(\$)\end{array}$ \\
\hline 1: MO process of $1 \mathrm{t} / \mathrm{d}$ & $5,896,000$ & 538,000 \\
2: MO process of $2 \mathrm{t} / \mathrm{d}$ & $6,009,000$ & 740,000 \\
3: MO process of $5 \mathrm{t} / \mathrm{d}$ & $11,541,000$ & $1,537,000$ \\
4: MO process of $10 \mathrm{t} / \mathrm{d}$ & $19,719,000$ & $2,827,000$ \\
5: MO process of 40 t/d & $40,065,000$ & $9,821,000$ \\
6: $\mathrm{S}$ process of $1 \mathrm{t} / \mathrm{d}$ & $6,776,000$ & 610,000 \\
7: $\mathrm{S}$ process of $2 \mathrm{t} / \mathrm{d}$ & $8,337,000$ & 911,000 \\
8: $\mathrm{S}$ process of $5 \mathrm{t} / \mathrm{d}$ & $12,063,000$ & $1,604,000$ \\
9: $\mathrm{S}$ process of $10 \mathrm{t} / \mathrm{d}$ & $19,545,000$ & $2,925,000$ \\
10: $\mathrm{S}$ process of 40 t/d & $37,978,000$ & $11,684,000$ \\
\hline
\end{tabular}

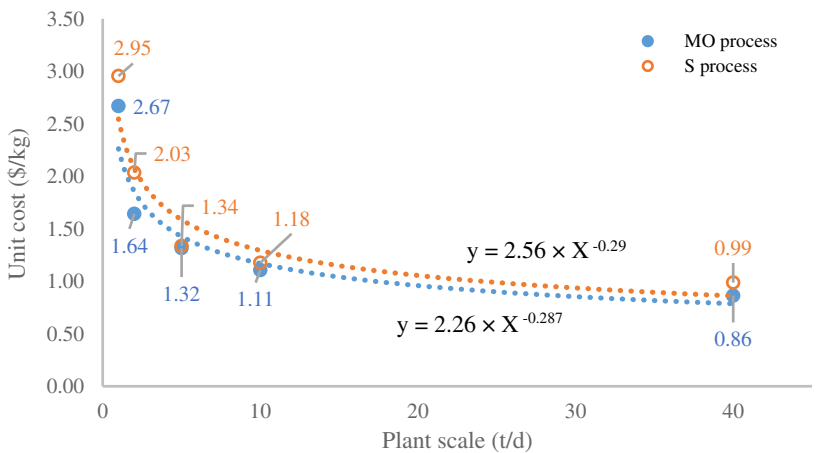

Fig. 2 Unit production cost for all ten scenarios explored in this study

\subsection{Other economic profitability analysis results}

Gross margin is the difference between revenues and the cost of goods sold as mentioned in previous. As shown in Table 4, Scenario 5 has the highest gross margin (31\%), while Scenario 6 has the lowest gross margin (-73\%). Scenario 1, 2, 6, and 7 have negative gross margin, while larger scale plants (Scenario 3-5 and Scenario 8-10) have positive outcome. The final product of all scenarios is UF adhesive (50 wt\%), but the by-products are different. In Scenario 1-5 (MO process), formic acid is produced; in Scenario 6-10 (S process), carbon monoxide and carbon dioxide are formed. Due to the various selling price of these by-products, Scenario 1-5 have higher gross margin compared with that from $S$ process. In terms of ROI, Scenario 1, 6, and 7 have the negative results. This indicates that the net profits obtained from these scenarios are negative; in other words, if adopting such scenario, it is possible that no profit could be made. As for the other scenarios, Scenario 5 has the highest ROI result (10.45\%), which means this scenario has the highest profit. As for the

Table 4 Profitability analysis results of gross margin, return on investment and payback time

\begin{tabular}{lccl}
\hline Scenario & $\begin{array}{l}\text { Gross mar- } \\
\text { gin (\%) }\end{array}$ & $\begin{array}{l}\text { Return on } \\
\text { investment (\%) }\end{array}$ & $\begin{array}{l}\text { Payback } \\
\text { time } \\
\text { (years) }\end{array}$ \\
\hline 1: MO process of $1 \mathrm{t} / \mathrm{d}$ & -57 & -1.74 & $\mathrm{~N} / \mathrm{A}$ \\
2: MO process of $2 \mathrm{t} / \mathrm{d}$ & -9 & 0.55 & $>30$ \\
3: MO process of $5 \mathrm{t} / \mathrm{d}$ & 11 & 2.42 & $>30$ \\
4: MO process of $10 \mathrm{t} / \mathrm{d}$ & 23 & 4.72 & 21 \\
5: MO process of $40 \mathrm{t} / \mathrm{d}$ & 31 & 10.45 & 10 \\
6: $\mathrm{S}$ process of $1 \mathrm{t} / \mathrm{d}$ & -73 & -1.25 & $\mathrm{~N} / \mathrm{A}$ \\
7: $\mathrm{S}$ process of $2 \mathrm{t} / \mathrm{d}$ & -29 & -0.91 & $\mathrm{~N} / \mathrm{A}$ \\
8: $\mathrm{S}$ process of $5 \mathrm{t} / \mathrm{d}$ & 9 & 2.24 & $>30$ \\
9: $\mathrm{S}$ process of $10 \mathrm{t} / \mathrm{d}$ & 16 & 3.68 & 27 \\
10: $\mathrm{S}$ process of $40 \mathrm{t} / \mathrm{d}$ & 17 & 6.52 & 15 \\
\hline
\end{tabular}




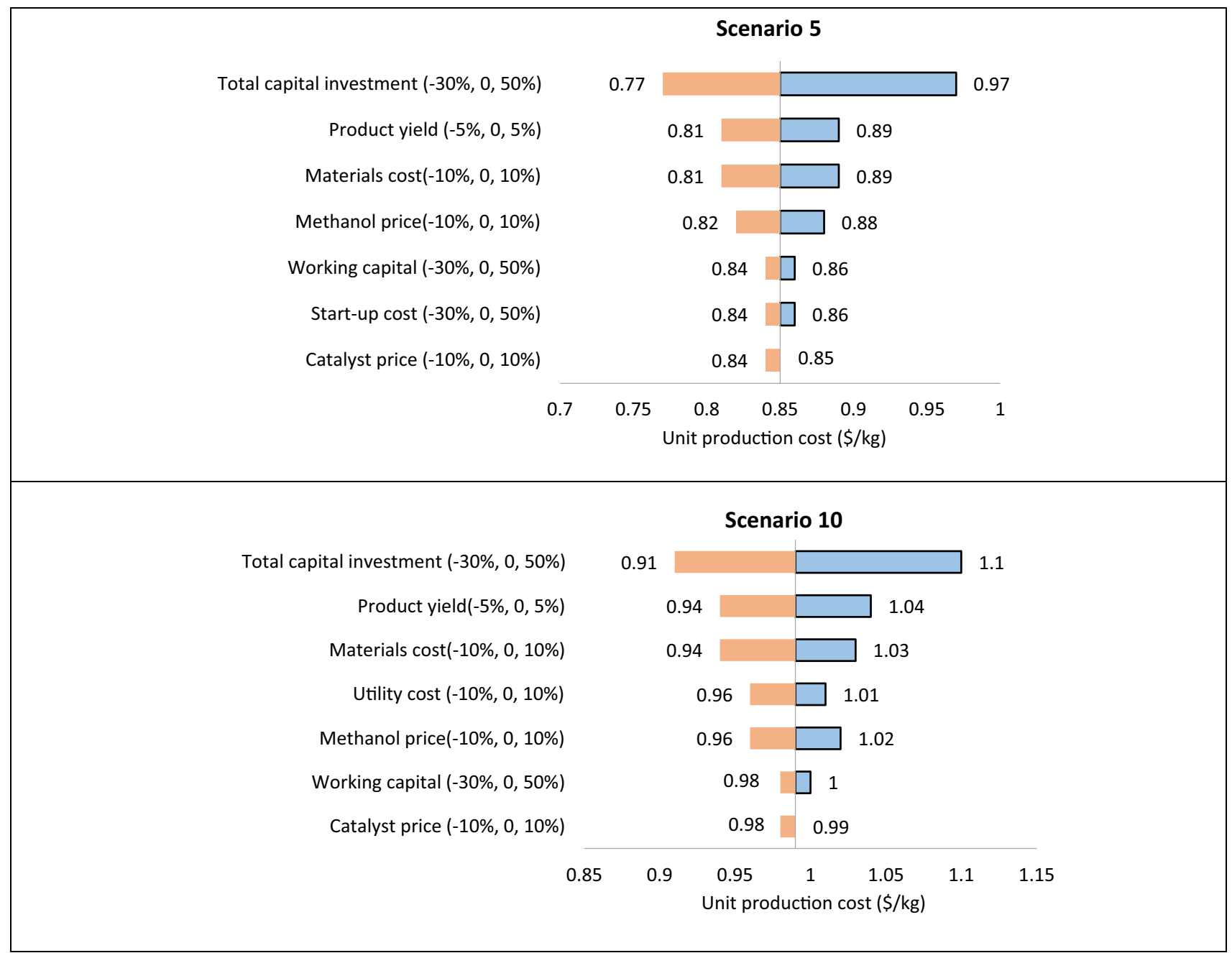

Fig. 3 Sensitivity analysis of metal oxide process (Scenario 5) and silver process (Scenario 10)

payback time, Scenario 5 requires the shortest (10 years). Under the same plant size, Scenario 10 requires 15 years.

\subsection{Sensitivity analysis}

Sensitivity analysis has been conducted in both Scenario 5 and Scenario 10. As illustrated in Fig. 3, the capital investment is the most sensitive variables among all input variables in terms of the unit production cost. The product value results from $\$ 0.77$ to $\$ 0.97 / \mathrm{kg}$. Product yield and material cost are the second most sensitive factors. With $5 \%$ more yield, the price will increase by $\$ 0.04 / \mathrm{kg}$. By exploring the raw materials used in this research, it is found that the price of methanol and catalyst have impact on the product value. As for the silver catalyst pathway (Scenario 10), total capital investment and product yield are also important factors for the unit production cost. Compared with metal oxide catalyst pathway, utility cost is the important sensitive factor for silver catalyst pathway.
This is mainly due to the higher temperature requirements $\left(\sim 600^{\circ} \mathrm{C}\right)$ in silver catalyst pathway.

\section{Conclusions}

In this study, the TEA of UF adhesive production process has been explored. Two pathways of formaldehyde production (metal oxide process and silver process) and five scales (from 1 to $40 \mathrm{t} / \mathrm{d}$ ) have been employed. Thus, ten scenarios have been studied and compared based on the developed techno-economic models. As a result, it is found that metal oxide catalysts pathway requires larger capital investment than silver catalyst pathway. However, the unit cost of metal oxide process was lower $(\$ 0.86 / \mathrm{kg})$ compared to silver catalyst pathway $(\$ 0.99 / \mathrm{kg})$. These selections of either process may depend on the initial capital investment of the project. 
Funding This study was funded by the National Institute of Food and Agriculture of the United States Department of Agriculture, under Project Number 214-38202-22318.

\section{Compliance with ethical standards}

Conflict of interest The authors declare that they have no conflicts of interest.

\section{References}

1. Kauffman GB, Stevens MP, Gent AN, Preston J, Rodriguez F, Bierwagen GP (1999) Major industrial polymers. https://www.brita nnica.com/topic/industrial-polymers-468698/Phenol-forma Idehyde\#ref608712. Accessed 08 Jan 2018

2. Ceresana (2015) Market study: adhesives —world (2nd edition). http://www.ceresana.com/en/market-studies/industry/adhes ives-world/. Accessed 14 Sept 2016

3. Polymer properties database (2015) Urea-formaldehyde resins. https://polymerdatabase.com/polymer\%20classes/UreaFormal dehyde\%20type.html. Accessed 09 Apr 2020

4. DIC (2016) Amino resins. http://www.dic-global.com/us/en/ products/amino/. Accessed 08 Jan 2018

5. Skeist I (1990) Handbook of adhesives. Springer, New York

6. Salamone JC (1996) Polymeric materials encyclopedia. CRC Press, Boca Raton

7. Gürü M, Tekeli S, Bilici L (2006) Manufacturing of urea-formaldehyde-based composite particleboard from almond shell. Mater Des 27(10):1148-1151. https://doi.org/10.1016/j.matde s.2005.03.003

8. Dunky M (1998) Urea-formaldehyde (UF) adhesive resins for wood. Int J Adhes Adhes 18(2):95-107. https://doi.org/10.1016/ S0143-7496(97)00054-7

9. Austin GT (1984) Shreve's chemical process industries. McGraw Hill, New York

10. Qian M, Liauw MA, Emig G (2003) Formaldehyde synthesis from methanol over silver catalysts. Appl Catal A Gen 238(2):211-222. https://doi.org/10.1016/S0926-860X(02)00340-X

11. Gayathri S, Muthamilarasi G (2005) Manufacture of formaldehyde from methanol. A project report. http://www.academia. edu/6244446/iii_MANUFACTURE_OF_FORMALDEHYDE_FROM_ METHANOL_A_PROJECT_REPORT. Assessed 10 Jan 2018

12. ICIS (2007) Formaldehyde production and manufacturing process. https://www.icis.com/resources/news/2007/11/05/90760 14/formaldehyde-production-and-manufacturing-process/. Accessed 09 Jan 2018

13. Que Z, Furuno T, Kotoh SN, Nishino Y (2007) Effects of urea-formaldehyde resin mole ratio on the properties of particleboard. Build Environ 42(3):1257-1263. https://doi.org/10.1016/j.build env.2005.11.028
14. Yang M, Rosentrater KA (2020) Cradle-to-gate life cycle assessment of structural bioadhesive derived from glycerol. Int J Life Cycle Assess. https://doi.org/10.1007/s11367-020-01733-9

15. Chau J, Sowlati T, Sokhansanj S, Preto F, Melin S, Bi X (2009) Techno-economic analysis of wood biomass boilers for the greenhouse industry. Appl Energy 86(3):364-371. https://doi. org/10.1016/j.apenergy.2008.05.010

16. Coker AK (2010) Ludwig's applied process design for chemical and petrochemical plants. Gulf Professional Publishing, Boston

17. Phoenix Equipment Corporation (2016) Formaldehyde resin plant-15,000 TPY. http://www.phxequip.com/plant.104/forma Idehyde-resin-plant-15-000-tpy.aspx. Accessed 22 Sept 2016

18. Yang M (2018) Life cycle assessment (LCA) and techno-economic analysis (TEA) of biobased adhesive derived from glycerol. Ph.D. dissertation, lowa State University, Ames, IA. https://lib.dr.iasta te.edu/etd/16695/

19. Wachs IE, Wang C (2000) Formaldehyde production. U.S. Patent 6147263

20. Kiser GL, Hendricks BG (1978) Formaldehyde manufacturing process. U.S. Patent 4076754A

21. Sanhoob M, Al-Sulami A, Al-Shehri F, Al-Rasheedi S (2012) Production of formaldehyde from methanol. Integrated Final Report, King Fahd University of Petroleum \& Minerals

22. Taylor D (1985) Urea-formaldehyde resin manufacture. England Patent 4564667

23. Yang M, Rosentrater KA (2019) Techno-economic analysis of the production process of structural bio-adhesive derived from glycerol. J Clean Prod 228:388-398. https://doi.org/10.1016/j. jclepro.2019.04.288

24. Peters MS, Timmerhaus KD, West RE (2011) Plant design and economics for chemical engineers, 5th edn. McGraw Hill, New Delhi

25. Alibaba (2020) https://www.alibaba.com. Accessed 08 Apr 2020

26. U.S. Energy Information Administration (2017) Electricity power monthly with data for December 2016. https://www.eia.gov/ electricity/monthly/. Accessed 10 Jan 2018

27. U.S. Bureau of Labor Statistics (2016) Occupational employment statistics. https://www.bls.gov/oes/current/oes_ia.htm. Accessed 15 May 2017

28. U.S. Department of Treasury (2017) Publication 946, how to depreciate property. https://www.irs.gov/publications/ p946/13081f34.html. Accessed 15 May 2017

29. Turton R, Bailie RC, Whiting WB, Shaeiwitz JA (2012) Analysis, synthesis, and design of chemical processes. Pretice Hall, New Jersey

30. Saltelli A, Ratto M, Andres T, Campolongo F, Cariboni J, Gatelli D, Tarantola S (2008) Global sensitivity analysis. Wiley, Hoboken

Publisher's Note Springer Nature remains neutral with regard to jurisdictional claims in published maps and institutional affiliations. 